\title{
A CONTRIBUTION TO THE STUDY OF THE PYRAMIDAL TRACT IN THE CENTRAL NERVOUS SYSTEM OF MAN.
}

\author{
BF WILLIAM G. SPILLER, M.D.
}

Profossor of Diseases of the Norvous System in the Philadelphia Polyclinic; Associate in the William Pepper Laboratory of Clinical Modicine, University of Pennsylvaria, U.S.A.

From the William Pepper Laboratory of Clinical Medicine.

(The Phebe A. Heahst Foumdation.)

IN the March, 1898, number of the Journal of Nervous and Mental Disease, Dr. H. A. Hare published a case of unusual œdema in hemiplegia. The brain from this patient was given to me by Dr. Hare and Dr. Harris, the pathologist who performed the necropsy. I was nofortunately unable to obtain the spinal cord, and the tract that I am about to describe could not be followed, therefore, below the lower part of the medulla oblongata.

I examined carefully the brain, and in a horizontal section made at the level of the superior part of the optic thalamus and candate nucleus I found a recent hemorrhage in the external capsule and lenticular nucleus of the left side. This hemorrhage appeared to be about the size of a hickory nut, and the brain substance around it was softened, more especially on the inner side of the focus. The anterior part of the posterior limb of the internal capsule was evidently involved in the softening, but the optic radiations, except perhaps in their most superior part, appeared, macroscopically, to be intact. In a section made horizontally through the left hemisphere, one inch below and parallel to the first section, no evidences of any lesion were seen. The case was a very suitable one for the Marchi method, 
as the patient had lived sufficiently long after the development of the hemiplegia for secondary degeneration to be well advanced.

I noticed in sections stained with osmic acid (Marchi's method) from the lower part of the medulla oblongata, a group of degenerated fibres lateral to the anterior horn. In tracing the tract towards its origin I used the greatest care to avoid mistake. The segments to be placed in Marchi's fluid of course had to be very thin, and to avoid the loss of a segment at any part where the tract might make a sudden bend, and, therefore, render the following of it difficult or impossible, I cut with the microtome each segment entirely before $I$ took another piece from the medulls oblongata. In this way I knew the position of the tract in the segments as they were successively studied, and was able to trace the tract to its separation from the degenerated pyramidal fibres; and at a point where it did make an abrupt bend I could follow it without any danger of error. It is not altogether easy to trace an unktown bundle throughout its course by the Marchi method, for the loss of a small segment may lead to confusion.

A brief description of my findings was published in a discussion of a paper by Dr. E. I. Mellas, read before the Philadelphia Neurological Society. ${ }^{1}$

The origin of the tract could not be determined. Its fibres were mingled with those of the degenerated pyramidal fibres arising in the left hemisphere, and as the lesion that caused the degeneration was on a level with the upper part of the optic thalamus, the tract in question must have arisen as high as the situation of this lesion. It may have arisen in the lenticular nucleus, or thalamus, or it may have come from the cortex. Very slightly below the level of the exit of the fifth nerve from the pons, a band of fibres could be seen distinctly separating from the outermost and lateral portion of the left pyramidal tract. This separation was at first gradual, and the two bundles remained close together for a short distance. Lower in the pons the more dorsolateral of these two tracts passed quite abruptly backward

'SpIrLeB. Joumal of Nervous and Mental Disease, March, 1899, p. 178. 
and slightly laterally, and entered the trapezoid body. At this portion of its course, in a transverse section, the bandle in passing backward formed a long and narrow band of horizontal lines of black dots, showing that the fibres were cut longitudinally. At the junction of the medulla oblongata and the pons it took a position lateral to the uppermost portion of the inferior olive. As the inferior olive increased in size, the bundle passed backward, and where the olive had its greatest width the bundle was on the posterior and lateral side of the lower olive, at the periphery of the medalla oblongata. The bundle remained on the left side below the motor decussation, but it could not be followed below the level of the first cervical segment, as the spinal cord could not be examined. The degenerated fibres forming this tract were numerous. In the medulla oblongata the position of the tract was very similar to that of Gowers' bundle.

Gowers' tract has been studied by many investigators, but Hoche says that his two cases (1896) were the first in which the tract in adult man could be traced to its termination in the cerebellum. Patrick traced it as far as the corpora quadrigemina.

According to Hoche, the extent of Gowers' tract, as shown by secondary degeneration, depends very much on the location of the lesion producing this degeneration. When the lesion is situated low in the cord the degeneration does not extend above the cervical region. The method of staining also makes a very great difference, as the fibres in the upper part of the tract are so scattered in places that the loss of these fibres is not detected by the Weigert hematoxylin stain.

Hoche refers to the fact that Gowers could not trace the tract above the upper part of the cervical swelling, and the lesion in his (Gowers') case was in the upper portion of the lumbar swelling; and that Schaffer could not trace it by the Marchi method above the second cervical root. If further investigations confirm these observations, Hoche thinks it is probable that only the fibres of Gowers' tract from the upper and middle thirds of the spinal cord are in relation with the cerebellum, and that those from the lower third of 
the cord connect cells within the cord at lower and higher levels, i.e., those within the lumbar and sacral region with those within the cervical. If this view is correct it seems reasonable to suppose that descending fibres may be contained within Gowers' tract.

The course of Gowers' tract as described by Hoche is very different from that of the tract seen by me. In the first place, Hoche was describing ascending. degeneration, from a lesion in the seventh thoracic segment in his first case, and I have observed descending degeneration. At the motor decussation the position of Gowers' tract as given by Hoche (fig. 3, case 1) corresponds with the position of my bundle. The position of the tract in figs. 5 and 6 is also similar to that of my bundle, but in fig. 7 (the level of the knee of the facial nerve) the resemblance ceases. From here on Gowers' tract, as described by Hoche, passes dorsally, and my tract passes ventrally.

Hoche could not trace Gowers' tract beyond the posterior corpora quadrigemina in either of his two cases, and be found that the tract turned upon itself and entered the cerebellum in such a way that in sections taken from the apper part of its course the tract was obtained at two different parts in the same section. The fibres of Gowers' tract entered the cerebellum partly in the velum medullare anticum, partly in the anterior cerebellar peduncle.

Below the primary lesion of the spinal cord in Hoche's first case, degenerated fibres were found in Gowers' column as far as within the lumbar region, but this does not prove that Gowers' tract degenerates downward.

The results obtained by Rossolimo in man are very different from those of Hoche. ${ }^{1}$ Rossolimo ${ }^{9}$ believed that Gowers' tract terminates in the posterior corpora quadrigemina, the substantia nigra and the globus pallidus. Quensel's $s^{3}$ paper is in support of Hoche's findings in great part.

Figures 1, 2, 3, 4 and 5 in Bruce's article show that the ventral cerebellar tract occupies a position similar to that of

1 Hoche. Archiv für Psychiatrie, vol. Irviii., 1896, p. 510.

3 Rossolimo. Neurologischas Centralblatt, 1898, p. 935.

- QDexser. Neurologisches Centralblatt, 1898, p. 482.

- Brdce. Bratr, vol. rai., p. 374 


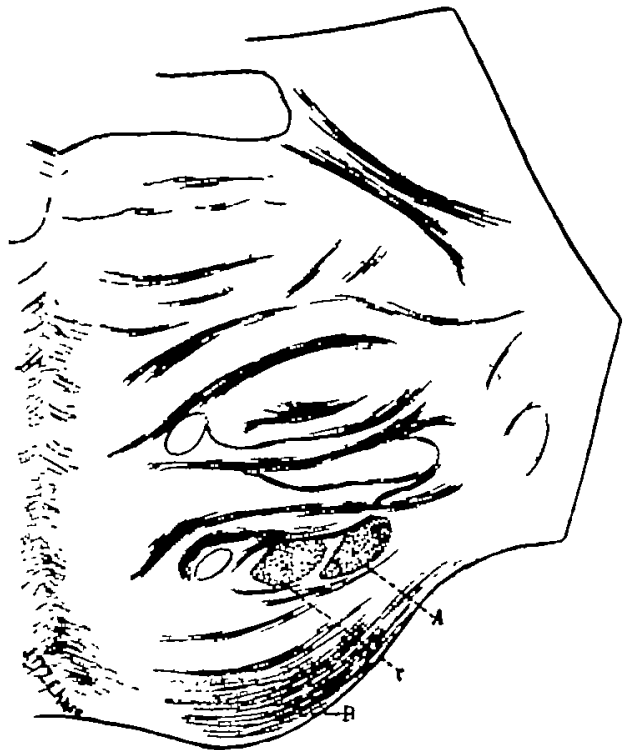

Fir. 6.

The degenerated bundle A has become aeparated from the adjoining fibres of the pyramidal tract in $\mathrm{C}$. B, fibres of middle cerebellar peduncle. Fig. 6 represents the position of the bundle seen in fig. 1.

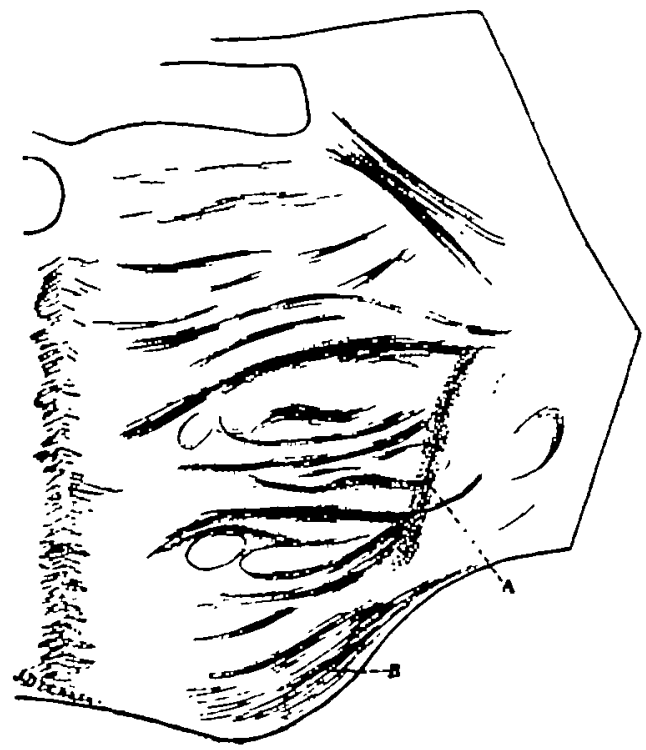

FIG. 7.

The bundle $A$ is seen in longitudinal section. Fig. 7 represents the position of the bundle seen in fig. 2 . 
my bandle in the medulla oblongata, bat in the pons the two tracts separate very widely.

In speaking of the afferent ventro-lateral tract, Russell ${ }^{1}$ says that the position of this tract in the fifth and all other

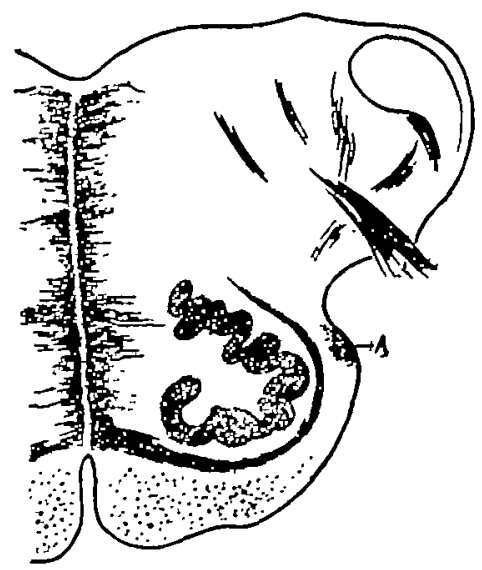

Fig. 8.

Fig. 8 shows the relation of the bundle $A$ to the lower olive.

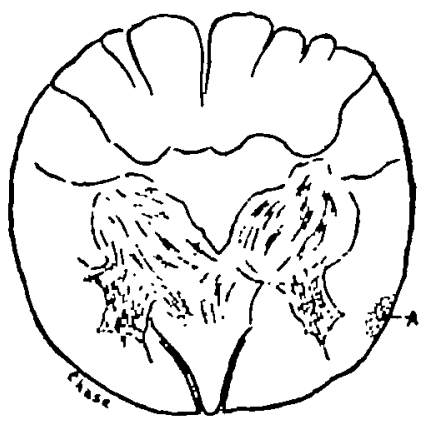

Fig. 9.

Fig. 9 shows the bundle $A$ at the lower part of the motor decussation. Fig. 9 represents the position of the bundle seen in fig. 4 .

segments of the cervical cord on the cephalic side of the lesion was more or less midway between the periphery of the cord and gray matter of the ventral horn, the band of tibres between this sclerosed area and the periphery of the cord

' Rossell. Brans, vol, xri., p. 170. 
being absolutely intact. This statement differs from those of most authors. My band of fibres in the upper cervical region is exactly on the periphery of the cord and this would seem to be a further proof that it is not a part of Gowers' tract.

Campbell, ${ }^{1}$ in his excellent digest on the tracts of the spinal cord, says Gowers' tract degenerates in an ascending direction, and he makes no reference to a descending degeneration of this tract. V. Bechterew thinks it is probable that in some cases in which a descending degeneration of Gowers' tract has been observed, the degeneration was really in Loewenthal's anterior marginal bundle, although $v$. Bechterew ${ }^{8}$ does not entirely exclude the possibility of descending fibres in the fasciculus antero-lateralis.

There seems to be considerable doubt as to whether Gowers' bundle does degenerate downward, and as far as I know no case has yet been reported in which this tract was degenerated in mon as the result of a cerebral lesion.

I find an interesting statement authorised by Schäfers in "Quain's Anatomy." It is said that in the monkey a few fibres of the antero-lateral column degenerate after lesions of the cerebral hemisphere of the opposite side. "They are mingled with those of the descending cerebellar tract and with those of the tract of Gowers, and are connected with cells in the Rolandic region of the cerebral cortex, as shown by the fact that they degenerate after lesions of that region. These fibres may perhaps be regarded as belonging to the system of the direct pyramidal tract, which in the monkey does not exist as a well-marked tract as in man: it has not yet been ascertained whether they occur in man as well as the direct pyramidal." These fibres are said to degenerate after a lesion of the opposite cerebral hemisphere.

Loewenthal ${ }^{4}$ described two bundles in the lateral column

I Caspelal. Brain, vol. xx., p. 522.

? . BECHTEREW. Die Leitungsbahnen im Gehirn und Rllckermark, second edition, pp. 82, 90.

" "Quain's Elements of Anatomy," vol. iii., part I., p. 25.

- Lozwenthal. Revue Medicale de la Suisse Romarde, 1886, p. 529.

VOL. XXII. 
of the cord in the cat and dog; one situated in the dorsal segment of the lateral column he called the intermediate system of the lateral column (système intermediaire du cordon latéral); the other, situated in the ventral segment of the antero-lateral column he called the anterior marginal bundle (faisceau marginal antérieur). He did not know the origin or termination of these tracts. This anterior marginal bundle might be thought to be the same as my tract, but recent investigations seem to indicate that Loewenthal's bundle comes from the cerebellum.

My tract could hardly be confounded with the intermediary system of Loewenthi. The major part of it does not occupy the mesial portion of the antero-lateral column in front of the lateral pyramidal tract. The literature on this tract is given by Campbell (l.c.) and v. Bechterew (l.c.).

The fibres in the peripheral part of the ground bundle of the antero-lateral column that degenerate downward, according to $\mathrm{v}$. Bechterew, are the spinal portion of the posterior longitudinal bundle and the fibres from Meynert's decussation that arise in the anterior corpora quadrigemina; the fibres of Forel's decussation that arise in the lateral portion of the thalamus and the nucleus ruber; the vorderes Randbündel that arises in the cerebellam; and finally the olivary tract, coming from the lower olive (l.c., p. 80 ).

By vorderes Randbündel, v. Bechterew means Loewenthal's faisceau marginal antérieur. From the investigations of Marchi, Biedl, and Basilewski (the latterin v. Bechterew's laboratory) v. Bechterew concludes that this tract arises in the cerebellum.

The tract described by v. Bechterew, ${ }^{1}$ Held, ${ }^{2}$ and Boyce, ${ }^{3}$ as arising in the anterior corpora quadrigemina, certainly could not be confused with my tract, and its location within the spinal cord is entirely different from that of the fibres observed by me. The tract arising in the thalamus is also very different (Boyce, v. Bechterew).

Risien Russell, in experimenting on dogs and monkeys,

I v. Bechterew. Neurologisches Centralblatt, 1897, p. 1074.

= HELd. Archio f. Anatomie u. Physiologie. Anatom. Abth., 1893, p. 289

- Borce. Neurologisches Centralblatt, 1894, p. 466. 
cut the lateral portion of the medulla oblongata between the " ascending" root of the fifth nerve and the inferior olive, and observed descending degeneration in the antero-lateral column. He regarded this tract as the same as that described by Boyce. This tract observed by Risien Rassell differs somewhat from the one seen by me. I can only compare the cervical region in each case, as I was unable to trace my tract below this region and Russell did not trace his above, on account of the location of the primary lesion. The fibres in my case occupied a very small portion of the area represented as degenerated in Russell's figure 2, and if Russell's tract was identical with that described by Boyce, as Russell believed, then its origin was very different from the origin of my tract. None of the degenerated fibres in my case were situated just ventrally to the crossed pyramidal tract and internally to the anterior part of the direct ascending cerebellar tract, as Russell ${ }^{1}$ described in his case.

My tract cannot be confused with that described by Marchi, Biedl, ${ }^{2}$ and Thomas, ${ }^{3}$ as arising in the cerebellum; elthough its position may be similar, its origin distinguishes it at once. It cannot be confused with the tract resulting from injury of Deiters' nucleus and other structures in the lateral region of the medulla oblongata (Ferrier and Turner, Risien Russell ${ }^{5}$ ) for the same reason; or with the fibres seen by Mott. ${ }^{\circ}$

Risien Russell has described a tract situated not very far from the position of my bundle. The case was one of tumour of the cerebrum. In addition to the degenerated pyramidal fibres studied by the Marchi method, he found another and quite distinct tract of degeneration seen on the side of the lesion, and occupying the ventral margin of the medulla, just outside and opposite to the ventro-external angle of the inferior olive. It was a well-defined band of

1 Russenc. Banis, vol. Ts., p. 409.

1 Biede. Neurologisches Cetralblatt, 1895, p. 434.

3 Thоmas. Le Ceroelet.

- Frereien and TUaser. Phil. Trans. Royal Soc., 1894, vol. clanv., B.

- Russell. Brair, vol. xx.

- Mott. Brant, 1895. 
degeneration, quite distinct and separate from the degenerated pyramid, lying between the external arcuate fibres as they course round the medulla opposite the inferior olive. Ruseell ${ }^{1}$ was anable to establish a connection of this tract with any of the degenerated fibres met with in the pons. A little lower in the medulla oblongata this tract was found in the lateral region opposite the ventral tip of the anterior horn. He believed that this tract was not derived from the degenerated pyramid.

This tract observed by Russell does not seem to be the same as the one observed by me. Russell was unable to satisfy himself as to the precise point of origin of his fibres. The position of the tract was not that occupied by the degenerated fibres in my case. It was at the periphery of the medulla oblongata and opposite the ventro-external angle of the inferior olive. My tract was also at the periphery but dorso-external to the inferior olive, and at some distance from the place occupied by Russell's fibres. In the cervical region Russell's tract seems to have occupied a more anterior position than mine.

In Thomas' recent review of certain descending tracts in the antero-lateral column I do not find the description of any tract exactly similar to mine.

I believe that the tract described in this paper has hitherto been unrecorded. If $I$ am in error in this $I$ shall cheerfally accept correction. One case may not be sufficient to establish the existence of an unknown tract, and should confirmation of my findings not be granted, I may have to assume that the bundle of fibres seen by me was an aberrant bundle from the pyramidal tract, and not usually present in the central nervous system. This explanation does not seem probable, but $I$ mention it in order to be as guarded as possible in all statements relating to scientific matters.

There are a few more tracts described by others that might be mentioned in this connection, but the resemblance to my bundle is not very great; such, for example, as the tract coming from the lateral fillet observed by Ferrier

1 Ressell. Brats, vol. rai., p. 145.

- THouss. Jourmal de Physiologie et de Pathologie Generale, No. 1, 1899. 
and Turner, ${ }^{1}$ or v. Monakow's" "aberrirendes Seitenstrangbündel " or Pick's bundle, which has been found by Hoche ${ }^{8}$ to degenerate downward.

The existence of homolateral fibres in the crossed pyramidal tract on the side of the cerebral lesion has been noted by a number of observers. The origin of these fibres in the degenerated pyramid of the same side seems to have been first observed in 1894 in a cat by Russell.4 The limited literature on the subject is given by him. I may add a reference to the paper by Dejerine and Long, and one to the paper by Redlich. ${ }^{6}$ In my preparations the origin of these homolateral fibres in the degenerated pyramid was distinct.

Dejerine and Long (l.c.) in cases of hemiplegia, studied by the Marchi method, observed degenerated fibres that left the anterior pyramid, took a horizontal course, mingled with the external anterior arciform fibres, passed in front of the arcuate nucleus, and decussated in the median raphe. These fibres were not traced beyond the interolivary layer of the opposite side. Similar fibres are also described by Redlich (l.c.) in experimental work.

The brain from a case of cerebral tumour was given to me by Dr. C. W. Burr. It was studied by the Marchi method. In addition to the usual degeneration of the pyramidal tract, I found degeneration of the postero-external columns, of equal intensity on the two sides, and the degeneration of the external anterior arciform fibres, described by Dejerine and Long, was very distinct. I was unable to follow these fibres beyond the interolivary layer of the opposite side.

I am indebted to Drs. C. Y. White and S. S. Kneass, associates in the Pepper Laboratory, for the photographs, and to Mrs. P. P. Chase for the drawings.

I Ferrier akd Tormer. Phil. Thans. Roy. Soc., 1894, vol. olnxw. B.

? v. Monskow. Archiv $f$. Psychiatrie, vols. xiv. and zaii.

- Hoche. Archiv für Psychiatrie, vol rax., 1898.

- Russell. Brain, vol. xxi., p. 145.

- Dejeane asd Lono. Comptes rendus de la Soc. do Biologio, 1898, p. 864 .

- Reduch. Neurologisches Centrabblatt, 1897. 


\section{DESCRIPTION OF FIGURES.}

Fig, 1.

The bundle $A$ is separated as a distinot band of degenerated fibres, and is seen in transverse section; at a little higher level it is united with the portion of the pyramidal tract designated by $\mathrm{D}$. Fibres of the middle cerebellar peduncle are seen on the extreme right of the photograph.

Fig. 2.

The bundle $A$ is seen in longitudinal section, with a low-power lens. It begins at this level to pass posteriorly. By mistake it is represented on the right side of the pons instead of on the left. Fibres of the middle cerebellar peduncle are seen at the lower left corner of the photograph.

Fra. 8.

(Same as fig. 2.) The bundle $A$ is seen under higher magnification, and the degree of degeneration, as indicated by Marchi's method, is shown.

Fis. 4.

The bundle $A$ is shown under low-power at the periphery of the cord, extending about as far forwards as the anterior end of the anterior horn (E). The anterior horn is seen on the left of the photograph. The bundle $A$ is, by mistake, represented on the right side of the cord instead of on the left.

Fig. 6.

(Seme as fig. 4.) The bundle $A$, which is somewhat indistinct in fig. 4, on account of the low-power lens employed, is seen in this photograph under higher magnification.

Figures $6,7,8$, and 9 are diagrams showing the relative position of the bundle A. 


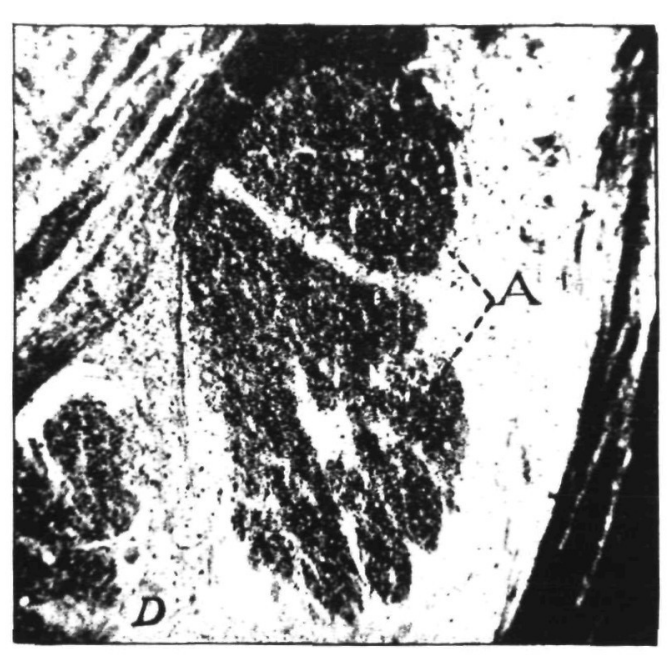

FIo. 1.

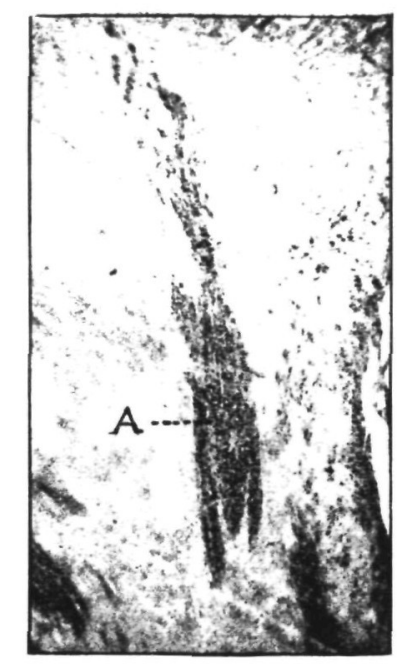

Fio. 2.

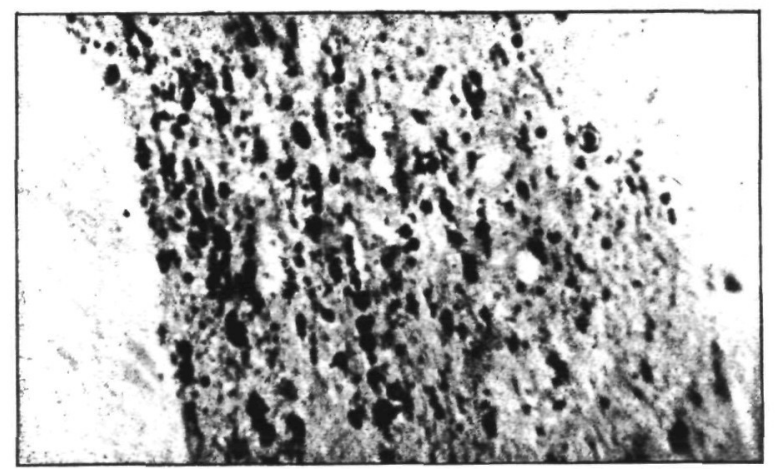

Fig. 3.
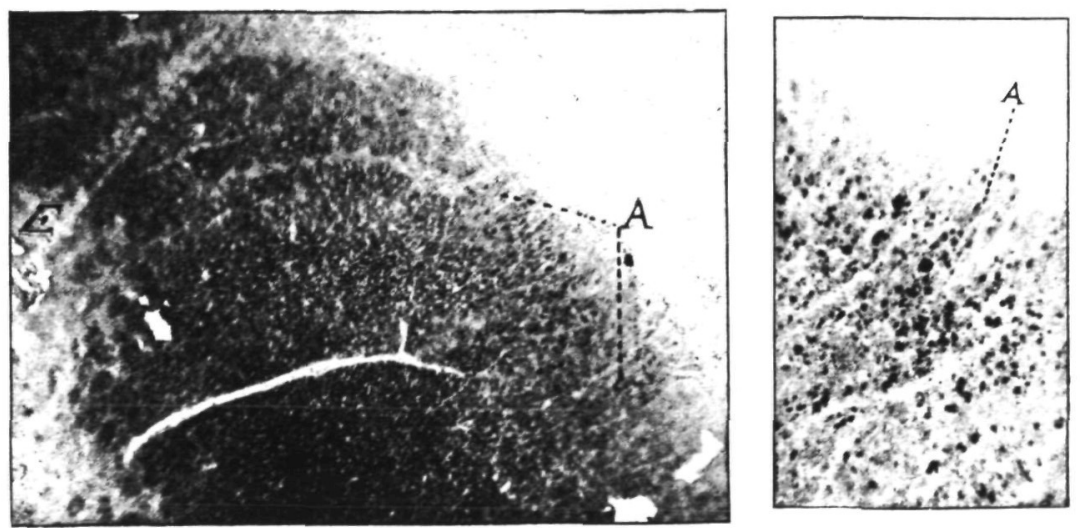

FIG. 4.

Fig. 5. 
